\title{
Physical Behavior of Thermally Affected Bronze and Brass
}

\author{
Samiul Kaiser ${ }^{1}$ and Mohammad Salim Kaiser ${ }^{2 *}$ \\ ${ }^{1}$ Department of Civil Engineering, Bangladesh University of Engineering and Technology, \\ Dhaka-1000, Bangladesh \\ ${ }^{2}$ Directorate of Advisory, Extension and Research Services, Bangladesh University of Engineering \\ and Technology, Dhaka-1000, Bangladesh, Tel.: +88-02-9663129; Fax: +88-02-9665622 \\ *Corresponding author: mskaiser@iat.buet.ac.bd
}

\begin{abstract}
The physical behavior of thermally affected cast copper, aluminum bronze and brass has been studied by subjecting to heating isochronally for one hour at a range of $600^{\circ} \mathrm{C}$. It shows that solid-solution hardening takes place into the $\mathrm{Al}$ added bronze and $\mathrm{Zn}$ added brass metal. Due to heating $\mathrm{Al}$ forms hard and brittle intermetallic of copper aluminates into the bronze metal which responses some age-hardening effects. The electrical conductivity of the metals increases initially through heat treatment due to stress relieving and finally decreases due to formation of intermetallic precipitates. The color of the heated samples are also studied through tristimulus color parameter ' $\mathrm{L}^{*}$ ', ' $\mathrm{a}^{*}$ ', and ' $\mathrm{b}^{*}$ ' values which were analyzed and evaluated in MATLAB software. It is found that incorporation of $\mathrm{Al}$ and $\mathrm{Zn}$ affects the color of cast $\mathrm{Cu}$. The overall change of color occurs with increasing heating temperature due to chemical changes like oxidization, intermetallic formation, dissolution of phases, precipitation coarsening and recrystallization. Due to change of hardness and microstructural properties of the experimental metals, the sound intensity level also decreases at high heating temperature. A microstructural study confirms that the cast alloys content the different phases of grains and bring about recrystallized status under heating at $500^{\circ} \mathrm{C}$ for one hour.

Copyright @ 2020 . Journal of Mechanical Engineering Science and Technology

All rights reserved
\end{abstract}

Keywords: Conductivity, color, Cu-alloys, microstructure, precipitates, sound

\section{Introduction}

Achieving the better properties alloying elements are applied to pure metal [1-3]. Alloying has a significant impact on increasing or reducing the different physical, mechanical and electrical properties, namely hardness, strength, corrosion, electric and thermal conductivity of metal $[4,5]$. The elements are added for improving one property which may affect other properties inadvertently. Here, a good procedure is solid solution strengthening of copper [6]. Al bronze is an alloy where aluminum is added to copper. The resulting alloy shows stronger and harder behavior than both of pure metals. Addition of zinc to copper forms brass which also follows the same. But $\mathrm{Al}$ is more effective rather than $\mathrm{Zn}$ in case of strengthening copper and also has a greater detrimental effect on electrical and thermal conductivity $[7,8]$. Compositions vary, but most modern bronze consists of up to $12 \% \mathrm{Al}$. In case of brass metal which range of available solid-solution compositions up to $35 \% \mathrm{Zn}$. Tin, $\mathrm{Mg}$, Ni and Si can also be added to strengthen copper [9-11].

However, variation in color is found when alloying elements are added to $\mathrm{Cu}$, which depends on the composition. Pure copper shows a reddish-brown appearance. Brass consists of zinc, iron and lead, and its color can differ from reddish to greenish to brownish-gold 
depending on the varying amount of those constituents. Nickel silver, formed by nickel, zinc, iron, lead and manganese, may have a grayish-white to silver appearance [12,13]. Apart from uniqueness in color, copper also has great sound producing characteristics. Because of this property, it is used as the main ingredient in cymbals. Sn, Ni or Zn at least one or other elements are alloyed to copper for producing the cymbals. The trace amount silver may be included in the alloys for better performance, but they are carefully controlled to avoid degradation in sound potential $[14,15]$.

This study expresses the role of alloying elements on copper-based alloys such as aluminum bronze and brass on physical properties like hardness, conductivity, color, sound, microstructure etc. under different heating condition. The equal ten weight percent of each $\mathrm{Al}$ and $\mathrm{Zn}$ alloying element was added into copper to isolate the influence of a single alloying element on different properties.

\section{Material and Methods}

The present study was involved with copper, aluminum bronze and brass metals. Commercial pure copper of $3000 \mathrm{gm}$ was used to develop the experimental copper. Pure copper of $2700 \mathrm{gm}$ and pure aluminum of $300 \mathrm{gm}$ was used for developing the aluminum bronze and similarly pure copper of $2700 \mathrm{gm}$ and pure zinc of $300 \mathrm{gm}$ was taken for brass. They were melted in a clay-graphite crucible at $1300 \pm 15^{\circ} \mathrm{C}$ with the help of natural gas-fired pit furnace. A steel mould of $20 \times 100 \times 150$ in millimeter was prepared. It was coated inside with a film of water-clay and preheated at $200^{\circ} \mathrm{C}$. Then the melts were homogenized by stirring and poured at $1200^{\circ} \mathrm{C}$ in that preheated mould. The chemical compositions of cast copper, bronze, and brass were analyzed by spectrochemical method, and it is listed in Table 1. A shaper machine was used to skin out the surface of the cast samples, and $3 \mathrm{~mm} \times 20$ $\mathrm{mm} \times 20 \mathrm{~mm}$ size of coupon was produced from the samples for microhardness and electrical conductivity measurement. Similarly, the dimension of $8 \mathrm{~mm} \times 25 \mathrm{~mm} \times 35 \mathrm{~mm}$ and $5 \mathrm{~mm} \times 65 \mathrm{~mm} \times 75 \mathrm{~mm}$ was produced for measuring the optical properties and sound intensity level, respectively. The alloy samples were isochronally heated at different temperatures up to $600^{\circ} \mathrm{C}$ for one hour. The samples were polished with $\mathrm{SiC}$ abrasive papers of rough one and then the finish one of 1500 grits. After each heat treatment, the microhardness measurements were performed on the polished samples with a Micro Vickers Hardness Tester. One $\mathrm{Kg}$ load for 10 seconds was used for the Knoop indenter. At least seven reading of hardness were taken from different places for each sample. Electrical conductivity of those heat-treated samples was also measured using a Type 979 Electric Conductivity Meter.

The images of the heated samples are taken with DSLR camera for examine the visual changes. The images of the samples are analysed through MATLAB software for determining the tristimulus color parameter ' $\mathrm{L}^{*}$ ', ' $\mathrm{a}^{*}$ ', and ' $\mathrm{b}^{*}$ ' values. The changes of these values with respect to different temperatures are shown graphically. A wooden platform was used to measure the sound intensity level of these bell-metal plates. The differently heated metal plates were hanged through a pair of chain and a bearing ball of stainless steel was used to imply force on the metal plates to create sound. An industrially usable digital sound level meter of model "Digital Sound Level Meter AS804" was used to measure the sound intensity level. The optical metallographic examinations were performed in the standard method. The highly polished specimens were etched in a solution containing Ammonium Hydroxide and Hydrogen peroxide (3\%) in 1:1 ratio. The microstructures of etched samples 
were examined using an optical microscope, and some micrographs were viewed and captured.

Table 1. Chemical composition by wt $\%$ of experimental copper, bronze, and brass metals

\begin{tabular}{lccccccccccc}
\hline Metal & Al & $\mathbf{Z n}$ & $\mathbf{P b}$ & $\mathbf{S n}$ & $\mathbf{F e}$ & $\mathbf{N i}$ & $\mathbf{M n}$ & $\mathbf{S i}$ & $\mathbf{C r}$ & $\mathbf{S b}$ & $\mathbf{C u}$ \\
\hline Copper & 0.001 & 0.000 & 0.010 & 0.004 & 0.033 & 0.001 & 0.000 & 0.000 & 0.001 & 0.000 & Bal \\
Bronze & 9.601 & 0.023 & 0.013 & 0.009 & 0.078 & 0.007 & 0.009 & 0.004 & 0.007 & 0.079 & Bal \\
Brass & 0.013 & 10.300 & 0.012 & 0.007 & 0.057 & 0.005 & 0.009 & 0.004 & 0.007 & 0.005 & Bal \\
\hline
\end{tabular}

\section{Results and Discussions}

\section{Isochronal heating}

The variation of microhardness after heating isochronally at different temperature of copper, bronze, and brass metals are shown in Fig. 1. It is observed that Al added bronze metal had shown marginally ageing response. Pure $\mathrm{Cu}$ and $\mathrm{Zn}$ bearing brass metal have however shown a continuous softening at increasing heating temperatures, with the sudden drop of hardness beyond $250^{\circ} \mathrm{C}$. The experimental results clearly designate that the ageing response exposed by the bronze metal is due to addition of Al. During casting and heating, various intermetallic phases are formed by the reaction of $\mathrm{Al}$ and $\mathrm{Cu}$. Specially $\mathrm{Al}_{4} \mathrm{Cu}_{9}$ and $\mathrm{Cu}_{3} \mathrm{Al}_{2}$ intermetallic are responsible for the higher hardness of the bronze metal [16]. In case of brass metal, higher hardness is attributable to solute hardening of the zinc solute atoms. Softening occurs at initial stage of heating due to stress reliving. At midway stage of heating, bronze metal shows a modest decrease of the hardness due to dissolve of GP zones before formation of metastable phase into the bronze metal [17, 18]. At the high heating temperature, the structures with coarse grains and increased size of precipitates responsible for lower hardness.

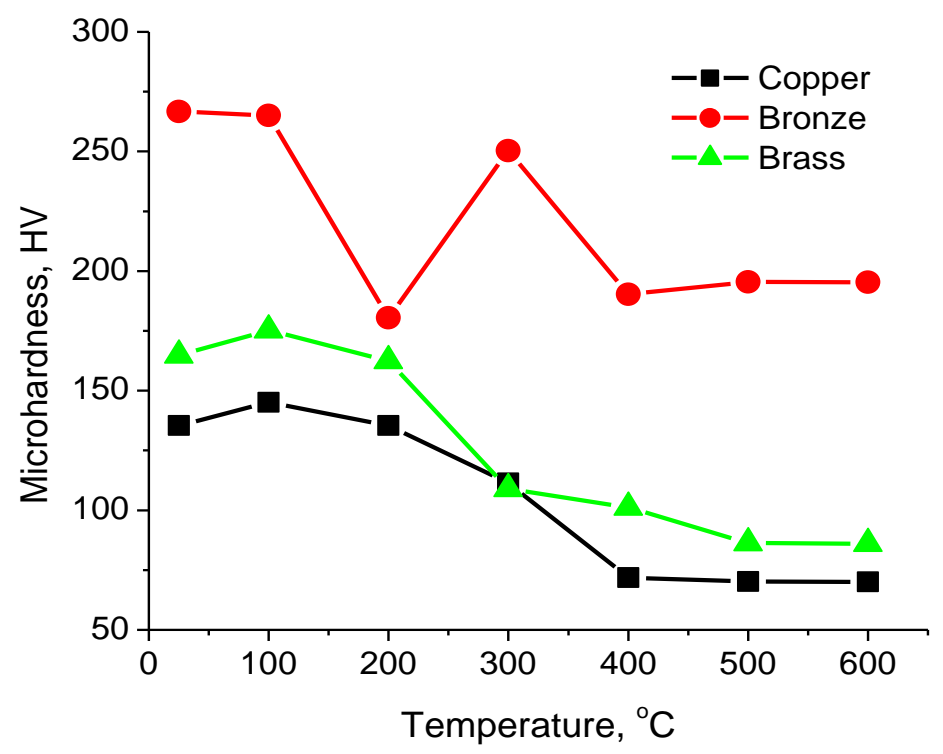

Fig. 1. Variation of microhardness due to isochronally heating of copper, bronze, and brass for one hour 
The variation of electrical conductivity under different heating temperature of the copper, bronze, and brass metals are depicted in Fig 2. Initial increase of conductivity is due to stress relieving in the experimental metals. After heating at high temperature, the subsequent drop in conductivity is due to the formation of fine precipitates [19].

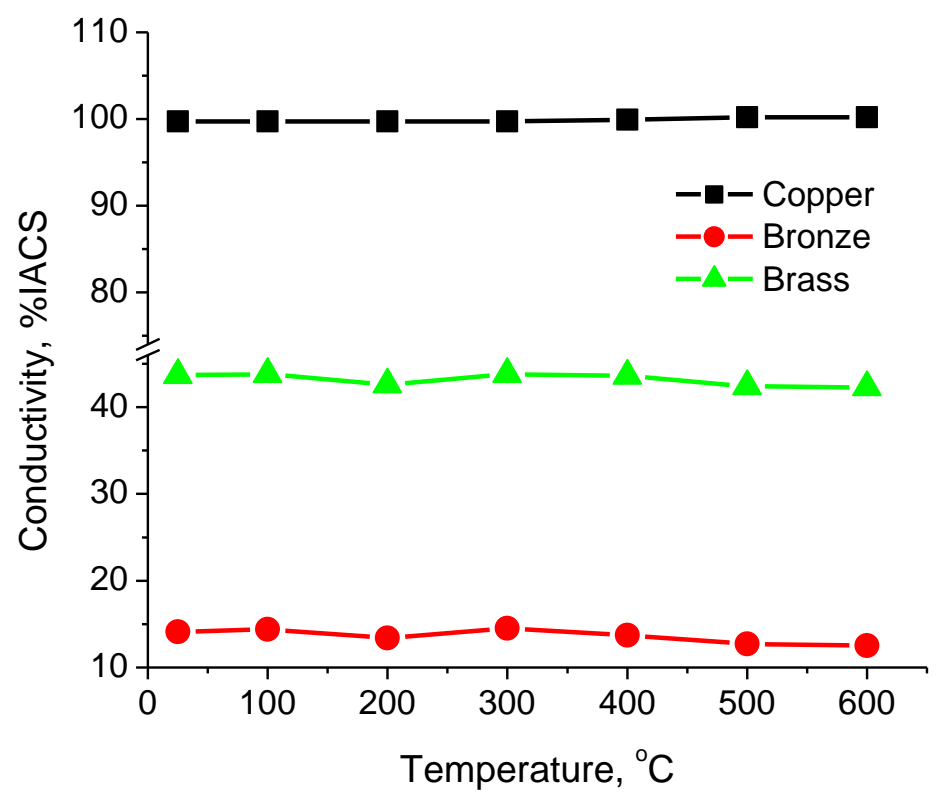

Fig. 2. Variation of thermal conductivity due to isochronally heating of copper, bronze, and brass for one hour

\section{Color behavior}

Due to heating of copper, bronze, and brass metal, the change of color is examined by tristimulus color parameter ' $\mathrm{L}^{*}$ ', ' $\mathrm{a}$ ' ' and ' $\mathrm{b}$ ') values which are plotted in Fig 3 to Fig 5 respectively. The ' $\mathrm{L}^{*}$ ' value vs heating temperature graph shows that up to $100^{\circ} \mathrm{C}$, there is an increase in ' $\mathrm{L}^{*}$ ' value (Fig 3 ). Beyond this temperature, the value starts to decrease greatly up to $250^{\circ} \mathrm{C}$ and then shows an increase at the higher temperature. The ' $\mathrm{a}^{*}$ ' value vs heating temperature graph indicates the increase of ' $\mathrm{a}^{*}$ ' value up to $100^{\circ} \mathrm{C}$ and then a minute decrease at higher heating temperature (Fig 4). At the initial stage the change of ' $b$ *' value shows a similar increased fashion of ' $\mathrm{a} *$ ' up to $100^{\circ} \mathrm{C}$ (Fig. 5). The higher heating temperature at $500^{\circ} \mathrm{C}$ shows a sudden increase of ' $\mathrm{b}$ *' values. This study has demonstrated that the increases of ' $\mathrm{L}^{*}$ ' values of the experimental metals due to oxide formation on the surface at a temperature of $100^{\circ} \mathrm{C}$. In case of copper, it delayed because of the oxygen diffuse into copper at $200^{\circ} \mathrm{C}$ in the air [20]. At the intermediate stage of heating, the decrees of ' $\mathrm{L}^{*}$ ' values occurs due to dissolution of some phases present into experimental metals. Final stage of heating the bronze and brass metals show the higher ' $\mathrm{L}^{*}$ ' values because of precipitation formation [21]. After heating at $100^{\circ} \mathrm{C}$, ' $\mathrm{a}^{*}$ ' and ' $\mathrm{b}$ ' ' values of the experimental metals change because of surface oxidation. With the increasing of heating temperature, the oxide layer also enlarged, up to a point. Then the layer begins to decompose as the copper gives up the oxygen faster than it reacts. At higher heating temperature, the metal begins to burn from complete heat. At the initial stage a dull, almost invisible red, then a very visible red, then the beginning of orange, and then it melts [22, 23]. 


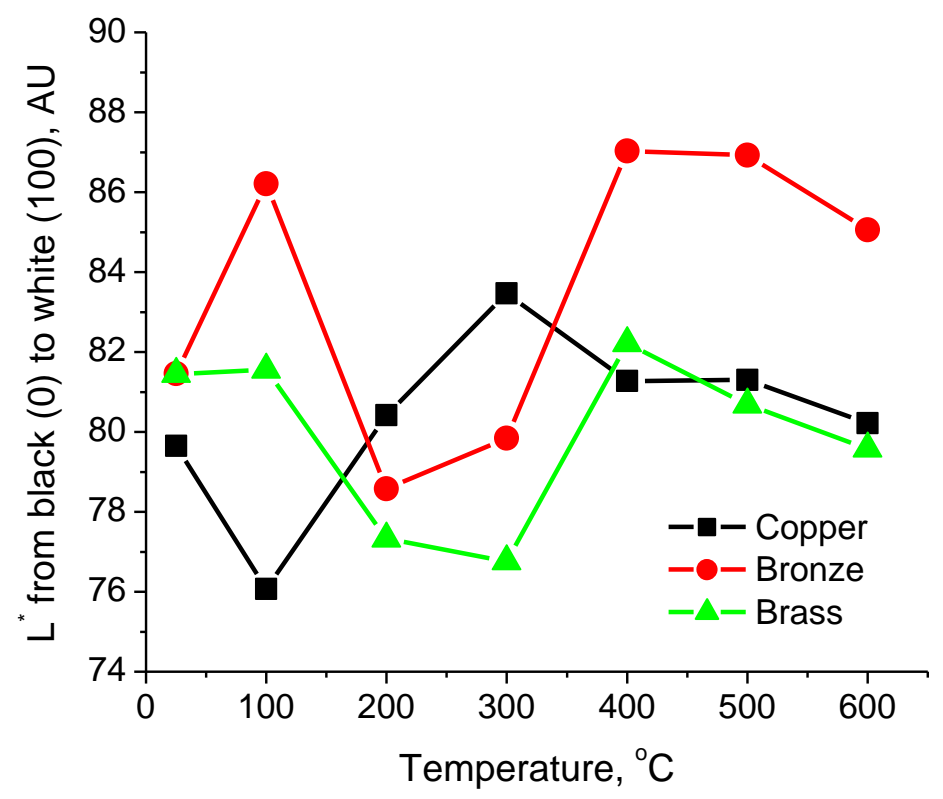

Fig. 3. Change of tristimulus color parameter $L^{*}$ due to isochronally heating of copper, bronze, and brass for one hour

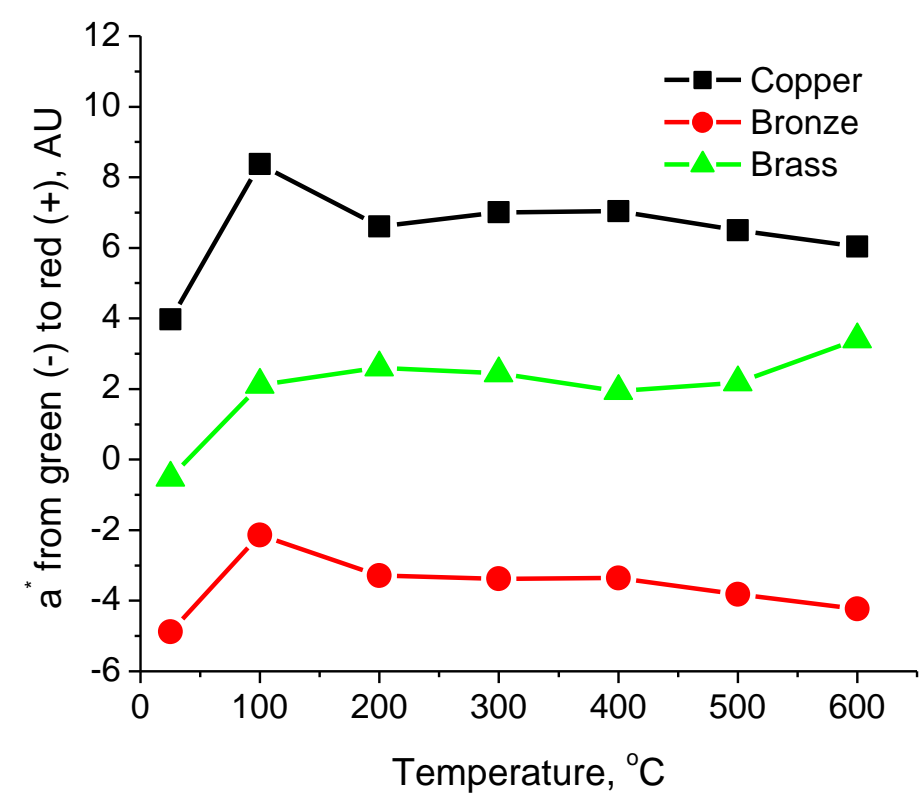

Fig. 4. Change of tristimulus color parameter a* due to isochronally heating of copper, bronze, and brass for one hour 


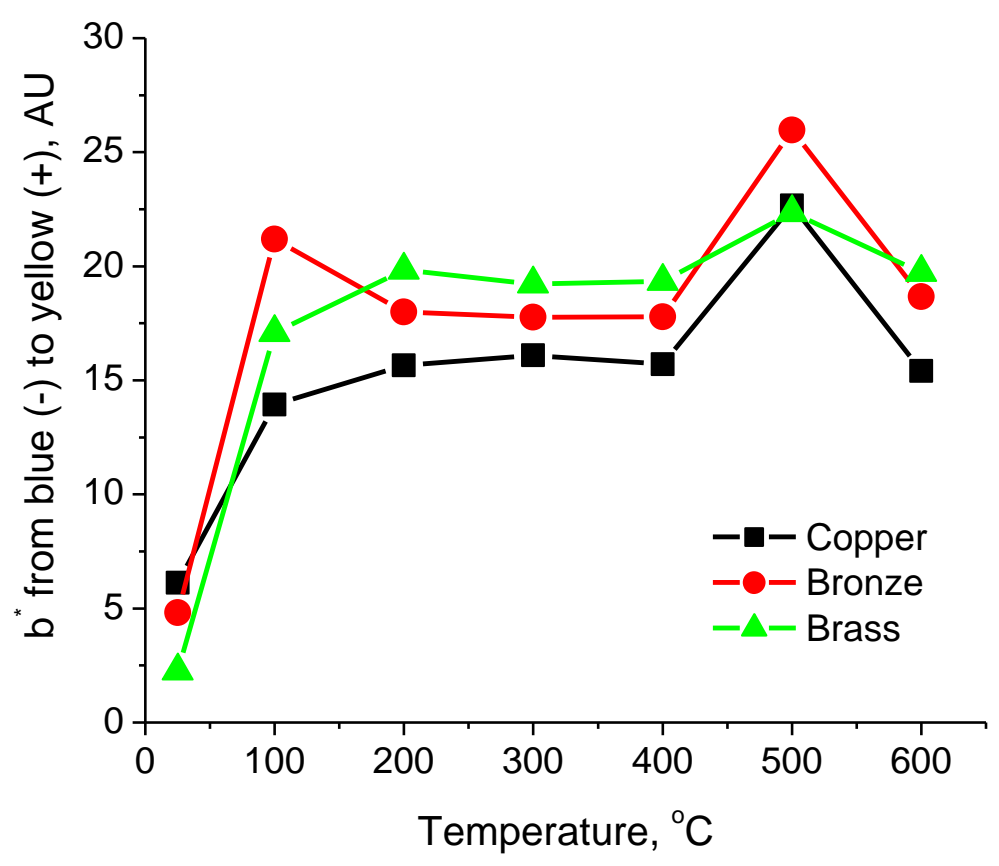

Fig. 5. Change of tristimulus color parameter $b^{*}$ due to isochronally heating of copper, bronze, and brass for one hour

\section{Acoustic response behavior}

Variation of sound intensity level with heating temperature of cast copper, bronze, and brass metal are representing in Fig. 6. At the room temperature, the sound intensity level is almost close for all the metal. Clearly pure copper creates lowest sound intensity with heating temperature, and sudden drop of sound intensity is observed beyond $400^{\circ} \mathrm{C}$. In the case of bronze and brass initially improvement of sound level due to precipitates formation and decreases at high temperature due to precipitates coarsening and recrystallization. $\mathrm{Zn}$ added brass metal shows a continuous increase from its initial value in acoustic response during impact with the increase in heating temperature up to $400^{\circ} \mathrm{C}$ and after that it also suddenly drops which follows the pattern of hardness curve discussed in the previous investigation. This occurred because of precipitation coarsening and recrystallization effect. Al added bronze metal shows better response than brass at higher heating temperature due to higher hardness $[15,24]$. Pure materials typically show the lower strength compared to those which are alloyed with other elements. The alloying elements form different intermetallic phases into the alloys, which reduce the movement of dislocations within the structure. In case of bronze and brass $\mathrm{Al}$ and $\mathrm{Zn}$ go to interstitial sites in the lattice which make the obstruction of dislocation movement. So, bronze and brass are achieved the higher strength compared with pure copper. It is also responsible for the formation of grain structure and sizes as well as alloy hardness. Very hard, homogenous and extremely durable materials are always favorable for producing inferior sound [25, 26].

Observed from the intensity comparison, the sample with $100 \%$ concentration had FF from direct light with the value of 0.9557 divided by 70,000 lux resulted in $1.04 \times 10^{-6}$ value. Meanwhile, the indirect light FF was $1.535 \times 10^{-6}$, based on the division of 0.00455 by 10,000 lux. The largest FF occurred in the sample with indirect light, and the lowest was 
from direct light. The results were inversely proportional considered the largest intensity from direct light. However, the indirect light had a small efficiency of $0.049863 \%$ compared to $1.499137 \%$ from direct light. The first concern correlated to the high energy usage but low FF and high efficiency. The second was the small energy usage but large FF ratio and small efficiency. All the phenomena are described in Figure 9.

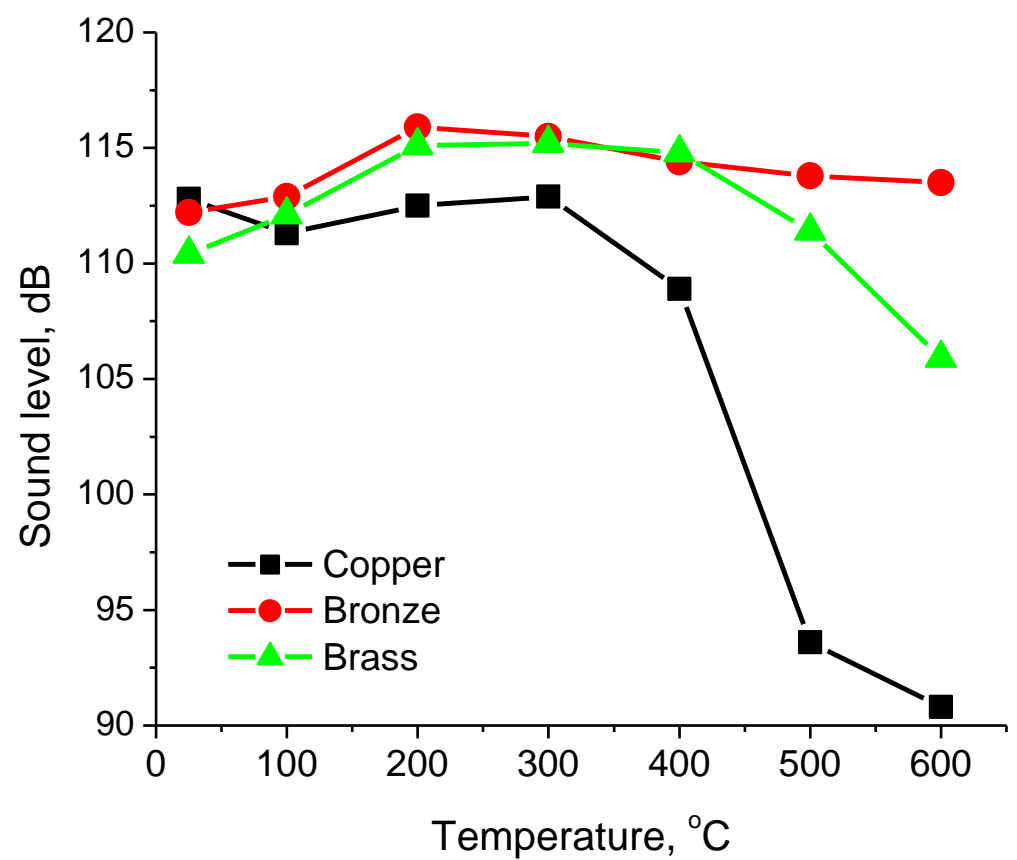

Fig. 6. Variation of sound level due to isochronally heating of copper, bronze, and brass for one hour

\section{Optical images observation}

The optical images of copper, bronze, and brass samples heated at different temperatures were recorded, and they are put on show in Figure 7. The images demonstrate that the varying temperature plays a great role in the color deviation of the samples. After heating at $100^{\circ} \mathrm{C}$, the color change is noticeable, and it is because of surface oxidation as well as the evaporation of water molecules from the surface [27, 28]. At room temperature, polished copper is a reddish-brown color. Initially forms a brown-black layer of cuprous oxide and next a blue-green layer of cupric oxide. With increasing the heating temperature, the oxide layer also enlarges. These layers display a fixed color for individual metals. After heating at $500^{\circ} \mathrm{C}$, the colour has changed drastically because of the chemical change through recrystallization and grain growth of the experimental materials [29]. Finally, the sample has got its natural state in terms of color. 


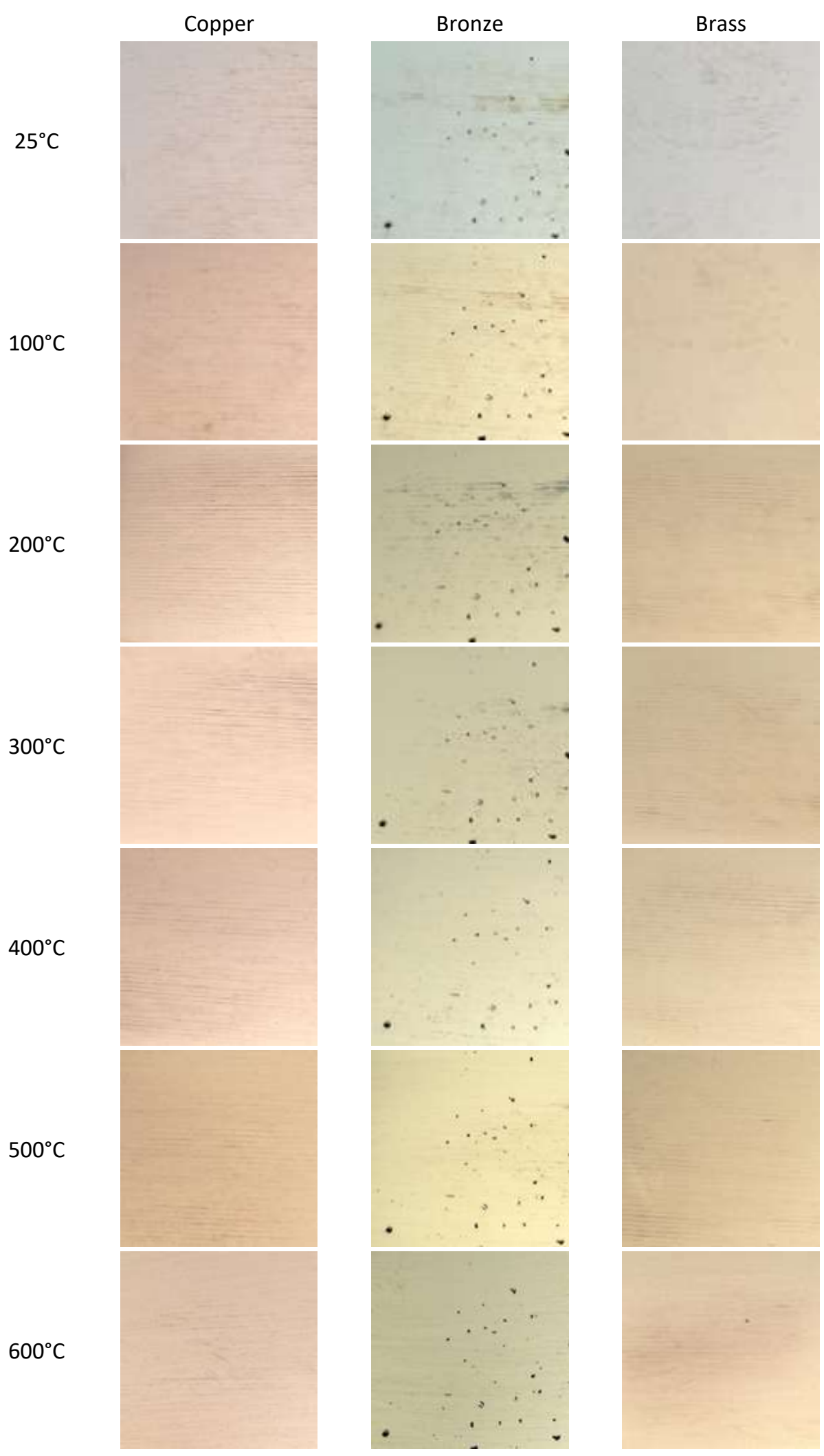

Fig. 7. Optical images of the color variation due to isochronally heating of copper, bronze, and brass for one hour 


\section{Optical microscopic observation}

The optical microstructure of cast $\mathrm{Cu}, \mathrm{Al}$ bronze and brass metals is shown in Fig. 8. The microstructure of cast copper usually consists of very different sizes of non-uniform grains (Fig. 8.a). It is because of the reactivity nature of coppers as the surface cracking, porosity, and the formation of internal cavities are high [30]. The microstructure of $\mathrm{Cu}-10 \mathrm{Al}$ is found to consist of three phases, namely $\alpha$-phase, $\beta$-phase or retained martensitic $\beta^{\prime}$-phase and surrounded by four different types of Fe-rich intermetallic numerous K-phases (Fig. 8.b) [31]. The microstructure of $\mathrm{Cu}-10 \mathrm{Zn}$ alloy reveals the presence of a single solid phase which consists of a solid solution of zinc in alpha copper (Fig. 8.c). This is predictable as zinc has a complete solid solubility in copper up to $35 \%$, which is well documented on the $\mathrm{Cu}-\mathrm{Zn}$ phase diagram [32].
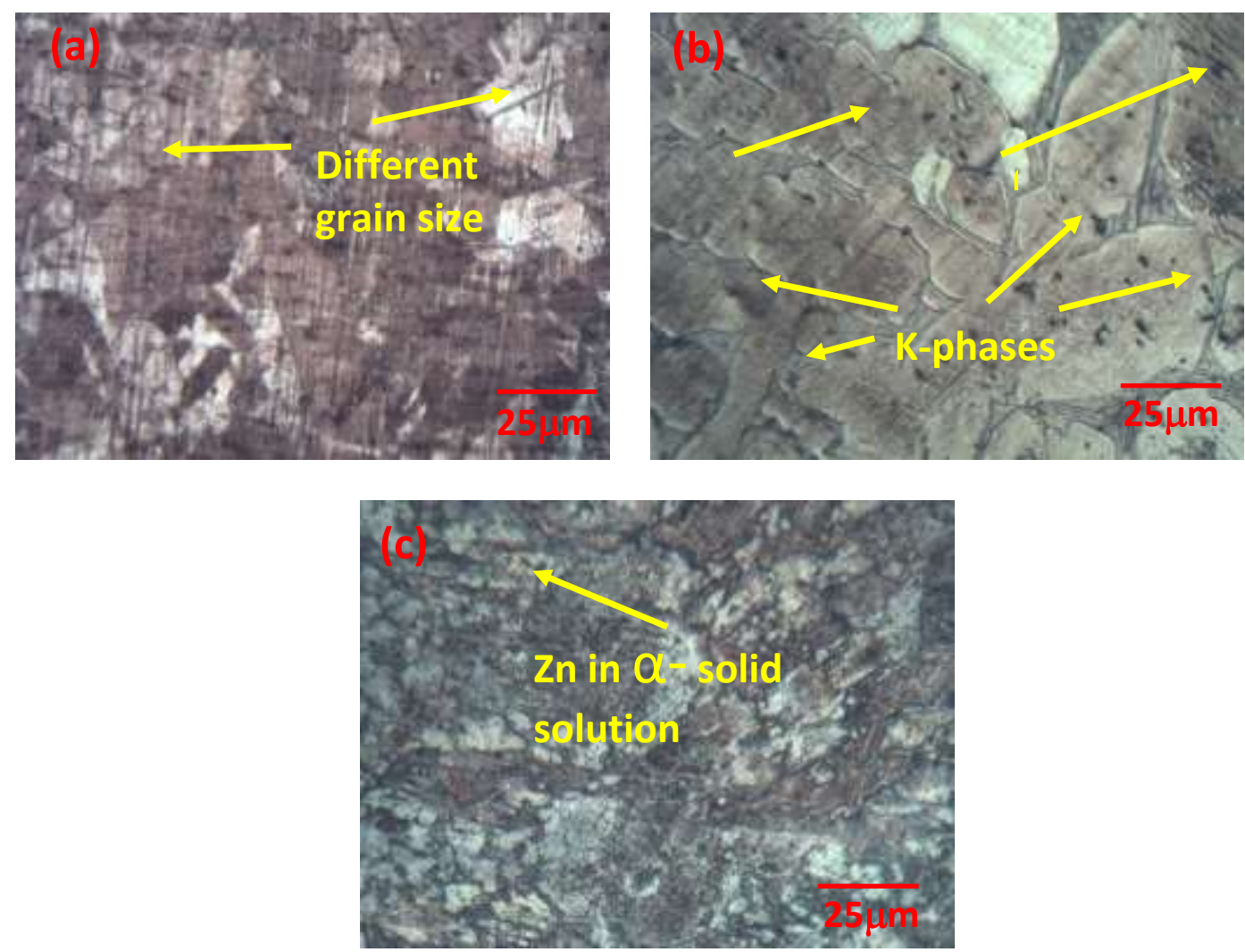

Fig. 8. Optical micrograph of cast a) copper, b) bronze, and c) brass

Fig. 9 shows the optical micrographs of the experimental alloys after heated at $500^{\circ} \mathrm{C}$ for one hour. Copper grains consist of some annealed twins because of recrystallization behavior of $\mathrm{Cu}$, and those annealed twins traverse through the grain completely (Fig. 9.a) [33]. The microstructure of $\mathrm{Cu}-10 \mathrm{Al}$ alloy at the same heat-treated condition contains large numbers of $\kappa$ precipitates (Fig. 9.b). The portion of the $\alpha$ phase into the microstructure becomes amplify. The spaces between polyhedral grains begin to resemble a discontinuous network. The grains consist of annealing twins with circular particles of $\kappa$ precipitate. Dendritic structure with a few precipitates may be visible. From Fig. 9.c it can be seen that heated at $500^{\circ} \mathrm{C}$ for one hour $\mathrm{Cu}-10 \mathrm{Zn}$ alloy grain size of is higher than the original pure copper due to grain growth at elevated temperature. Grains with a few twins and precipitates 
on boundaries are observed for the heated alloy. The microstructure is a mixture of recrystallized grains and coarse non-recrystallized grains. A homogenized recrystallized microstructure is observed in $\mathrm{Cu}-10 \mathrm{Zn}$ alloy as well as in pure $\mathrm{Cu}$.
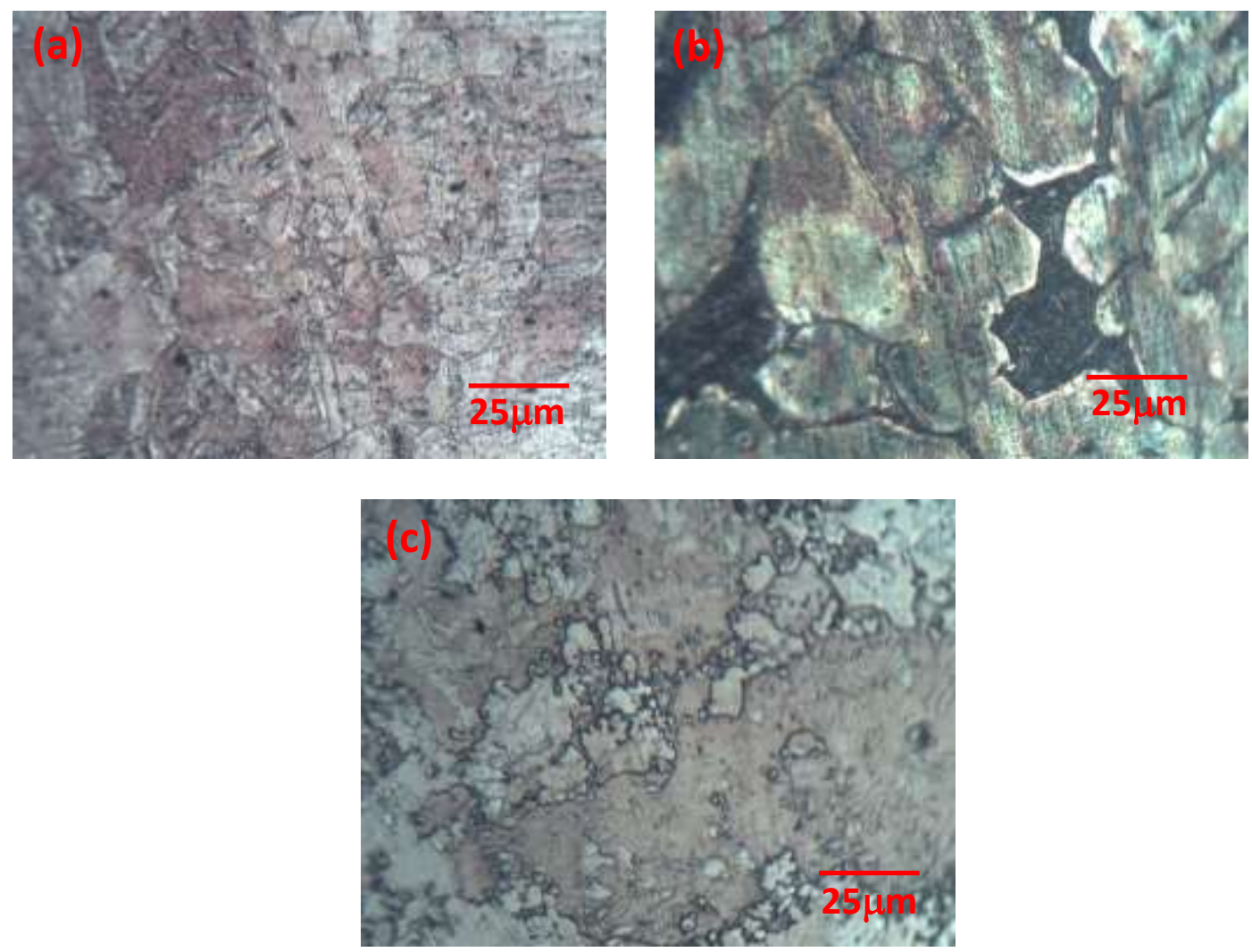

Fig. 9. Optical micrograph of cast alloys heated at $500^{\circ} \mathrm{C}$ for 1 hour, a) copper, b) bronze, and c) brass

\section{Conclusion}

Pure copper, aluminum bronze, and brass metals were obtained by casting flowed by isochronally heating for one hour at different temperature regimes. From the experimental results, it is understandable that the presence of $\mathrm{Al}$ and $\mathrm{Zn}$ significantly increases the hardness of bronze and brass due to solid-solution hardening. Additionally, Al forms hard and brittle intermetallic during heating which improves the hardness of the bronze metal. As a result sound property also improved. In the case of color behavior, it is also improved through the addition of alloying elements like $\mathrm{Al}$ and $\mathrm{Zn}$. As cast microstructure shows different phases of grains but heating at $500^{\circ} \mathrm{C}$ for 60 minutes all the alloys reach recrystallized state.

\section{Acknowledgement}

All the facilities were provided by the Directorate of Advisory, Extension and Research Services of Bangladesh University of Engineering and Technology, Dhaka-1000 which are gratefully praised and acknowledged. 


\section{References}

[1] H. Chandler, "Metallurgy for the Non-Metallurgist," ASM International, 4th edition, Materials Park, OH, USA, 2006.

[2] S. Kaiser, and M.S. Kaiser, "Wear Behavior of Commercial Pure Copper with Al and Zn under Dry, Wet and Corrosive Environment," Journal of Materials and Environmental Sciences, vol. 11 (4), pp. 551-563, 2020.

[3] J.A Rogers, "Dispersion-Strengthened Copper Alloys with Useful Electrical and Mechanical Properties," Powder Metallurgy, vol. 20 (4), pp. 212-220, 1977.

[4] M. Kanamori, S. Ueda, "The Effect of Alloying Elements on the Properties of CopperAluminium-Nickel-Iron Quaternary Cast Alloys," Transactions of the Japan Institute of Metals, vol. 1 (2), pp. 103-107, 1960.

[5] S. Kaiser and M.S. Kaiser, "Investigation of Mg and $\mathrm{Zr}$ Addition on the Mechanical Properties of Commercially Pure Al," International Journal of Mechanical and Materials Engineering, vol. 13 (9), pp. 607-611, 2019.

[6] J. Ridhwan, M. Syafiq, R. Hasan, Z.M. Zulfattah, "Effect of Ageing on the Microstructures and Mechanical Properties of C102 Copper Alloy," Journal of Engineering and Technology, vol. 4 (2), pp. 115-124, 2013.

[7] M. Sadayappan, D. Cousineau, R. Zavadil, M. Sahoo and H. Michels, "Grain Refinement of Permanent Mold Cast Copper Base Alloys,” AFS Transactions, vol. 110, pp. 505-514, 2002.

[8] G.E. Totten, "Heat Treating of Nonferrous Alloys," ASM International, vol. 4E, West Conshohocken, USA, 2016.

[9] S. Kaiser and M.S. Kaiser, "Influence of Aluminium and Zinc Additives on the Physical and Thermal Behaviour of Cast Copper," Journal of Sustainable Structures and Materials, vol. 3 (1), pp. 1-9, 2020.

[10] H.E. Boyer, "Heat Treating of Nonferrous Alloys," Metallography, Microstructure, and Analysis, vol. 2 (3), pp. 190-195, 2013.

[11] K. Ri, V.G. Komkov and E.K. Ri, "Effect of Alloying Elements on the Physicomechanical Properties of Copper and Tin Bronze," Russian Metallurgy, vol. 9, pp. 750-755, 2014.

[12] J.L. Fang and G. McDonnell, "The Colour of Copper Alloys," Historical Metallurgy, vol. 45 (1), pp. 52-61, 2011.

[13] M. Modlinger, M.H.G. Kuijpers, D. Braekmans and D. Berger, "Quantitative Comparisons of the Color of CuAs, CuSn, CuNi, and CuSb Alloys," Journal of Archaeological Science, vol. 88, pp. 14-23, 2017.

[14] L.L. Rokhlin, V.S. Shkirov and M.P. Uralskij, "Acoustical Properties of Copper and Copper Base Alloys,” Defektoskopiya, vol. 1, pp. 61-66, 1974.

[15] J. Audy and K. Audy, "Analysis of Bell materials: Tin Bronzes," China Foundry, vol. 58 (1), pp. 77-81, 2009.

[16] E. Altuncu, S. Iric and F. Ustel, "Wear Resistant Intermetallic Arc Spray Coatings," Materials and Technology, vol. 46 (2), pp. 181-183, 2012.

[17] D. Zhang, Y. Li, K. Feng, P. Zhu and G. Xu, "Effect of Aging Temperature on 
Microstructure and Mechanical Property of Aluminium Brass," IOP Conf. Series: Materials Science and Engineering, vol. 452, pp. 1-5, 2018.

[18] M.S. Kaiser, "Solution Treatment Effect on Tensile, Impact and Fracture Behaviour of Trace $\mathrm{Zr}$ Added Al-12Si-1Mg-1Cu Piston Alloy," Journal of the Institution of Engineers, India, Series D, vol. 99 (1), pp. 109-114, 2018.

[19] I.R. Rodríguez, A.L. Guevara, M.S. Sicacha, J.C.M. Mosquera, M.R. Agudo, C.R. Gutierrez and M.R. García, "The Influence of the Precipitation Heat Treatment Temperature on the Metallurgical, Microstructure, Thermal Properties, and Microhardness of an Alpha Brass," Materials Sciences and Applications, vol. 9 (4), pp. 440-454, 2018.

[20] M. Walkowicz, P. Osuch, B. Smyrak, T. Knych, E. Rudnik, L. Cieniek L, A. Rozanska, A. Chmielarczyk, D. Romaniszyn and M. Bulanda, "Impact of Oxidation of Copper and Its Alloys in Laboratory-Simulatedconditions on Their Antimicrobial Efficiency", Corrosion Science, vol. 140, pp. 321-332, 2018.

[21] Y.P. Zhang, J.X. Zhang and J.S. Yu, "Quantitative Research on Color of Cu-Mn-Zn Alloys," Materials Transactions, vol. 43 (4), pp. 741-744, 2002.

[22] C. Leygraf, T. Chang, G. Herting and I.O. Wallinder, " The Origin and Evolution of Copper Patina Colour," Corrosion Science, vol. 157, pp. 337-346, 2019.

[23] M.S. Ahsan ann M.S. Lee, "Colorizing Mechanism of Brass Surface by Femtosecond Laser Induced Microstructures," Optik-International Journal for Light and Electron Optics, vol. 124 (18), pp. 3631-3635, 2013.

[24] J. Arts, "Changes in Pitch of Bells," The Journal of the Acoustical Society of America, vol. 22 (4), pp. 511-12, 1950.

[25] B. Lawson and W. Lawson, "Acoustical Characteristics of Annealed French Horn Bell Flares," The Journal of the Acoustical Society of America, vol. 77 (5), pp. 1913-1916, 1985.

[26] W. Duffy Jr, "Acoustic Quality Factor of Copper Alloys from $50 \mathrm{mK}$ to $300 \mathrm{~K}$," Journal of Applied Physics, vol. 86 (5), pp. 2483-2489, 1999.

[27] C.F. Hurn, "The Cause of the Colours Shown during the Oxidation of Metallic Copper," Proceedings of the Royal Society of London. Series A., vol. 115 (772), pp. 570-588, 1927.

[28] S. Kaiser and M.S. Kaiser, "Thermal Degradation of Enamel Paint Coating on Cement Plaster," 5th International Conference on Civil Engineering for Sustainable Development. Khulna, Bangladesh, February 7-9, 2020.

[29] S.K. Lee, H.C. Hsu and W.H. Tuan, "Oxidation Behavior of Copper at a Temperature below $300{ }^{\circ} \mathrm{C}$ and the Methodology for Passivation," Materials Research, vol. 19 (1), pp. 51-56, 2016.

[30] G. Benchaban, Z. Boumerzoug, T. Gloriant and I. Thibon, "Microstructural characterization and recrystallization kinetics of cold rolled copper," Physica B: Condensed Matter, vol. 406 (10), pp. 1973- 1976, 1973.

[31] M.S. Kaiser, "Ageing Behaviour of Minor Sc and Zr Doped Cast Cu-10Al Alloys", International Journal of Engineering and Information Systems, vol. 3 (11), pp. 7-14, 2019. 
[32] E.E. Igelegbai, O.A. Alo, A.O. Adeodu, and I.A. Daniyan, "Evaluation of Mechanical and Microstructural Properties of $\alpha$-Brass Alloy Produced from Scrap Copper and Zinc Metal through Sand Casting Process," Journal of Minerals and Materials Characterization and Engineering, vol. 5 (1), pp. 18-28, 2017.

[33] Y. Wu, S. Huang, Q. Chen, B. Feng, D. Shu and Z. Huang, "Microstructure and Mechanical Properties of Copper Billets Fabricated by the Repetitive Extrusion and Free Forging Process," Journal of Materials Engineering and Performance, vol. 28 (4), pp. 2063-2070, 2019. 